\title{
De Mulheres e Outras Ficções: contrapontos em antropologia e feminismo
}

\author{
Fabiana Maizza \\ Universidade de São Paulo (USP), São Paulo, Brasil \\ E-mail: fabianamaizza@gmail.com
}




\section{Resumo}

O artigo faz uma reflexão sobre a antropologia e o feminismo, conside-rando um como ponto de vista privilegiado para se pensar o outro. Meu fio condutor é a reflexão crítica sobre o corpo e a divisão sexo/ gênero presente tanto no pensamento feminista como na abordagem antropológica. Em um primeiro momento, como em um ensaio, explicita-se as questões levantadas pelos movimentos feministas para se pensar algumas das categorias analíticas utilizadas na antropologia; em seguida, reverte-se as posições e aponta-se para a contribuição de algumas descrições etnográficas sobre Melanésia, Egito e Amazônia - que problematizam temas centrais relacionados às teorias feministas, como 'corpo', 'sexo' e 'gênero'. Por um lado, o artigo visa defender o feminismo como posicionamento crítico na escrita etnográfica; e, por outro, visa refletir sobre os desafios às formulações Ocidentais colocados por outros pontos de vistas, advindos da própria pesquisa etnográfica.

Palavras-chave: Feminismos. Antropologia. Corpo. Etnografia. Marilyn Strathern.

\section{Abstract}

The article aims to make a reflection about anthropology and feminism taking one as a standpoint to think about the other. Throughout the article I try to have a critical approach to the concept of 'body' and to the 'sex/gender' division, found on the feminist studies as well as on the anthropological approach. In a first moment, as in an essay, I intend to discuss some of the analytical categories used in anthropology through questions brought up by the feminist movements; then, I revert positions and focus on ethnographic descriptions of Melanesia, Egypt and Amazonia, and on the problems they might bring to the feminist debate - as they question concepts such as 'body', 'sex' and 'gender'. At one hand, the article aims to defend feminism as a critical standpoint in the ethnographic writing; at the other, it wants to think about the challenges to Western formulations brought by other points of view, coming from the ethnographic research itself.

Keywords: Feminisms. Anthropology. Body. Ethnography. Marilyn Strathern. 


\section{Introdução}

O feminismo então se situa na 'diferença que faz' para outros aspectos da identidade de alguém

(Marilyn Strathern)

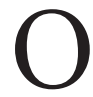
tenso relacionamento entre antropologias e teorias feministas é bastante conhecido para pesquisadoras/es que se interessam por ambas. Se imaginarmos um confronto caricatural e teatral, teríamos algo como as autoras feministas de um lado, acusando as antropólogas de terem e perpetuarem um pensamento burguês, conservador, masculino e heteronormativo. Já do outro lado, as antropólogas desconfiam de certo "etnocentrismo" do conhecimento feminista e de suas formulações que supõem um mundo comum compartilhado por povos distintos. Quando os argumentos do feminismo radical entram no debate, é sugerido que as antropólogas não podem formular e pensar questões em diálogo com trabalhos escritos por homens: é preciso romper com o patriarcado para mudar, inovar e simetrizar os poderes. As antropólogas recorrem e lembram às estudiosas feministas que seus escritos pressupõem que todos os povos possuem a mesma noção da pessoa e de corpo que nós, Ocidentais, e isso, segundo elas, estaria longe de ser o caso. O conhecimento feminista condena as antropólogas em usar a experiência das pessoas para interesses antropológicos, subordinando os textos aos usos da disciplina (Strathern, 2009, p. 99) e desconsiderando a grande assimetria entre as pessoas que escrevem e as pessoas sobre quem se escreve Antropologia. As antropólogas acham que os debates feministas impõem seus problemas às outras mulheres em nome de uma causa comum e nesse processo perde de 
vista o fato de que os problemas das mulheres não são os mesmos em todos os lugares (Strathern, 1988, p. 33).

Segundo Marilyn Strathern (2009), esses desencontros entre antropologias e feminismos podem ser entendidos através do uso que cada uma delas faz do conceito de experiência - essencial para ambas. No conhecimento feminista, especialmente no 'feminismo radical não antropológico' ao qual se refere a autora, a ideia de experiência é fundadora de qualquer posicionamento. O conhecimento feminista radical considera que a teoria feminista é "experiencial" (Keohane apud Strathern, 2009, p. 96): a experiência é pessoal e se torna um “[...] instrumento de conhecimento que não pode ser apropriado pelos Outros [...]" (Strathern, 2009, p. 97), apenas compartilhada por pessoas semelhantes. Para a construção de um eu feminista é necessário a consciência do outro não feminista, que seriam os "homens" e a dominação masculina no "patriarcado" (Strathern, 2009, p. 97-98). Os feminismos, como movimentos políticos e sociais, visam restaurar a subjetividade do eu dominado pelo outro por isso não há possibilidade de dividir experiências com o outro (Strathern, 2009, p. 97-98). O eu se torna consciente através da recuperação de um passado comum com o outro, um passado de opressão (Strathern, 2009, p. 99).

Já nas Antropologias, especialmente a "antropologia pós-moderna não feminista", a/o etnógrafa/o deve fazer a "tradução da experiência para forma textual" (Clifford, 2002): escrever sobre a experiência dos outros, revivendo os efeitos de sua própria experiência em campo. A distância com o outro deve ser mantida, mas o outro não está sob ataque, ao contrário: o esforço é o de criar uma relação com o outro (Strathern, 2009, p. 98), uma relação em que o eu é usado conscientemente como um veiculo para representar a um outro (Strathern, 2009, p. 99). Isso só é possível se o eu rompe com seu próprio passado (Strathern, 2009, p. 99).

Assim, os projetos e radicalismos feministas e antropológicos parecem ser bastante diferentes. No entanto, a revolução pela qual passou a Antropologia na década de 1980, e que ficou conhecida como 'pós-modernismo', deve bastante aos movimentos feministas. Em uma nota de rodapé na introdução de Writing Culture, James Clifford não apenas nega implicitamente qualquer dívida dos "pós-modernos" 
com os estudos acadêmicos feministas, mas afirma que "grupos por longo tempo excluídos de posições de poder institucional, como mulheres e pessoas 'não brancas' ${ }^{1}$, têm menos liberdade concreta para entrarem em experimentações textuais" (Clifford, 1986, p. 21, nota 11, tradução livre). O comentário foi rigorosamente rebatido por estudiosas feministas, resultando, entre outros, em livros como Women Writing Culture, organizado por Deborah Gordon e Ruth Behar e Writing Women's Worlds de Lila Abu-Lughod. No processo de criar/afirmar uma nova maneira de se pensar e, sobretudo, de se escrever antropologia, uma antropologia 'multivocal', James Clifford e seus colegas (quase todos homens), parecem não ter tido necessidade de teorizar sobre os modelos antropológicos embasados em moldes masculinos e sobre como a política da divisão sexual determina o que será escrito e valorizado nos cânones antropológicos ${ }^{2}$.

Como afirma Strathern, ao contrário do que foi sugerido por Clifford, os estudos acadêmicos feministas foram ao mesmo tempo percursores a, e uma manifestação de algumas das posições que ficaram conhecidas como "pós-modernas" (Strathern, 2004, p. 33). Algumas pesquisadoras/escritoras feministas anteciparam a experimentação contemporânea e em muitos sentidos foram além dela (Strathern, 2004). Como argumenta a autora, a insistência de Clifford sobre a 'natureza parcial da verdade antropológica', já estava presente na forma como feministas falavam umas com as outras de diferentes posições: a perspectiva feminista sendo necessariamente parcial (Flax apud Strathern, 2004, p. 33-34). Para a autora, isso se deve ao fato de que o conhecimento feminista, ao contrário do conhecimento antropológico, não tenta nem deseja ser acumulativo ou formar um corpo de conhecimento ao qual as/os pesquisadoras/es contribuem; ao contrário, os interesses são múltiplos e não precisam ser antagônicos ou reconciliados (Flax apud Strathern, 2004, p. 33).

De acordo com Donna Haraway, a própria "objetividade feminista" está vinculada à não totalização do eu: “O eu cognoscente é parcial em todas suas formas, nunca acabado, completo, dado ou original; é sempre construído e alinhavado de maneira imperfeita e, portanto, capaz de juntar-se a outro, de ver junto sem pretender ser outro. 
Eis aqui a promessa de objetividade: um conhecedor científico não procura a posição de identidade com o objeto, mas de objetividade, isto é, de conexão parcial" (Haraway, 1995, p. 26-27). A “objetividade feminista" trata da localização limitada e do conhecimento localizado; ela é uma 'objetividade corporificada' que se interessa pela posição, pela corporificação e pela perspectiva parcial (Haraway, 1995, p. 23-29).

Se inspirando no ciborgue de Haraway (1985) que relaciona diferença por conexões parciais, conexões sem suposições de comparação, Strathern sugere que o feminismo e a antropologia devem ser posições para se olhar o outro, cada uma constituindo uma posição para se olhar uma contraposição (Strathern, 2004, p. 35). Posições que não se completam nem se somam, nem são metades de um todo; mas sim posições que se relacionam por conexões parciais. Um é a extensão da capacidade do outro, como uma prótese entre uma pessoa e uma ferramenta: uma estende a outra, mas apenas pelo ponto de vista da outra (Strathern, 2004. p. 38), cada uma dá capacidades para a outra, a faz 'funcionar' (Strathern, 2004. p. 39). As propostas da antropologia e do feminismo não podem se desafiar porque não são substitutas uma da outra (Strathern, 2009, p. 102).

Baseada nessa forma de ver as possíveis relações entre feminismo e antropologia, propõe-se aqui a pensar dois temas caros, tanto às reflexões feministas como antropológicas: corpo e pessoa. A ideia é passar do feminismo à antropologia e da antropologia ao feminismo na tentativa em que uma tensione o outro em contraposição. Trata-se antes de tudo de um texto de caráter experimental: diferentes posições são experimentadas, sem pretensão a uma conclusão ou a um conhecimento acumulativo sobre os assuntos em discussão. De maneira ensaística recuperando textos, autoras e pressupostos - procura-se, enfim, fazer que uma posição coloque questões e problemas não cogitados a partir do outro ponto de vista. Enfatizo, no entanto, que apesar da aparente abrangência das discussões, o artigo se propõe a pensar, sobretudo, a questão de corpo e pessoa nos estudos feministas e na antropologia. Outros temas aparecerão como decorrência da própria conexão que fazem com esses dois temas, eles mesmos, parcialmente conectados entre si. O que se tem, então, são discussões às vezes emaranhadas, 
às vezes conectadas entre elas, que nos fazem sobretudo refletir sobre a forma como nós mesmos, antropólogos, antropólogas, formulamos e pensamos esses temas.

\section{Sexo e Gênero}

A não universalidade da categoria 'mulher' parece hoje fazer parte do senso comum Ocidental ${ }^{3}$. A obra fundadora dessa corrente do movimento feminista de que o gênero é uma construção social, ou de que "não se nasce mulher", é o livro O Segundo Sexo de Simone de Beauvoir. Na década de 1970, 20 anos depois da publicação do livro, a Antropologia contribui para a reformulação crítica da categoria 'mulher', providenciando exemplos etnográficos da variabilidade do gênero e dos papéis de gênero, e reforçando o posicionamento feminista de que o gênero não é biologicamente determinado (Moore, 1994, p. 10). No entanto, a diversidade na construção social do gênero não explicava a 'subordinação universal da mulher', e para lidar com esse assunto em particular a antropologia formulou duas importantes teorias comparativas (Moore, 1994, p. 10).

A primeira afirmava que a subordinação feminina, ou o 'estatuto secundário universal' da mulher, poderia ser entendido pelo fato das mulheres serem mais próximas da natureza do que os homens devido à "naturalidade do processo de nascimento" (Ortner, 1974, p. 75, tradução livre). Tudo começaria com o corpo e a especificidade feminina das funções procriadoras (Ortner, 1974). Em todas as sociedades, a 'cultura' estaria comprometida em gerar sistemas de formas significativas, para que a humanidade transcenda a existência natural (dada) e controle a 'natureza' em nome de seus interesses (Ortner, 1974, p. 72). Em todas as culturas, a 'natureza' seria de ordem inferior, e as mulheres seriam identificadas (ou simbolicamente associadas) à natureza devido a seus corpos reprodutores (Ortner, 1974, p. 73). Isso explicaria a submissão universal da mulher.

A segunda teoria também se baseava no corpo feminino, afirmando que a 'assimetria sexual universal' ocorria devido ao fato de que "a biologia dita que as mulheres irão ser mães" (Rosaldo, 1974, p. 23, tradução livre). A maternidade e os vínculos entre mães 
e filhos formariam o lado 'doméstico' da sociedade, que seriam “[... instituições mínimas organizadas imediatamente em torno de uma ou mais mulheres e seus filhos" (Rosaldo, 1974, p. 23, tradução livre). Já a esfera pública seria as instituições e as formas de associação que organizavam, agrupavam ou subsumiam grupos particulares do tipo mãe-filhos (Rosaldo, 1974, p. 23). As mulheres, devido a seus papéis de mães, seriam sempre absorvidas em atividades domésticas (Rosaldo, 1974, p. 24), e por isso, 'subordinadas' aos homens que organizariam a vida pública da sociedade ${ }^{4}$.

Essas teorias tiveram um grande impacto fora da antropologia e foram essenciais naquilo que ficou conhecido como "segunda onda do feminismo". O inovador dos textos de Ortner, Rosaldo e outras antropólogas, é que eles forneciam uma descrição social, e não biológica, da posição das mulheres na sociedade e das origens da diferença de gênero (Moore, 1994, p. 11). Assim se estabeleceu a poderosa distinção entre sexo e gênero: o sexo seria biologicamente dado, o gênero socialmente construído. No entanto, no processo da argumentação contra o 'determinismo biológico', a favor do 'construcionismo social', as autoras feministas, e as antropólogas, deixaram em suspenso a ideia subjacente de que existiriam inúmeras elaborações sociais para um fato supostamente único e autoevidente: a distinção natural dos sexos, dadas pelos corpos masculinos e femininos.

A diferença biológica entre os sexos parecia inquestionável, e assim “[...] as formulações de uma identidade essencial como homem ou como mulher permaneceram analiticamente intocadas e politicamente perigosas" (Haraway, 2004, p. 217-218). Perigosas, pois desconsideram, por um lado, a forma de construção de nossas categorias analíticas como natureza e cultura, indivíduo e sociedade; e, por outro, porque ignoram as consequências dessas dicotomias no discurso colonial ocidental (Haraway, 2004). Um discurso que estrutura o mundo em termos de apropriação dos recursos da natureza pela cultura, e da dominação daqueles que habitam as categorias "naturais", como mulheres, povos não brancos e o meio ambiente (Haraway, 1995, p. 36; Haraway, 2004). A estratégia do conhecimento feminista de separar sexo e gênero ao invés de desafiar os modelos dominantes Ocidentais, acabou por reproduzir os mesmos pressupostos nos quais 
estes modelos se baseiam (Yanagisako; Collier, 1987, p. 25, 49), olhemos mais de perto alguns dos mais conhecidos.

No pensamento Ocidental, o humano (o ser humano) é imaginado por meio de dois poderosos dualismos: natureza e cultura e do par terminológico fundador das Ciências Sociais, indivíduo e sociedade. Para nós, as pessoas são híbridos naturais, uma recombinação criativa de materiais genéticos já diferenciados, que faz com que cada pessoa, cada corpo, seja uma nova entidade. Assim, um 'homem' e uma 'mulher' procriam e geram um filho, um indivíduo, que é uma mistura desses materiais genéticos e ao mesmo tempo uma entidade diferente. Em nossa maneira de conceber a pessoa, concebemos o indivíduo: o indivíduo como uma entidade pré-formada, natural, que pode ser vista por meio do seu corpo. No discurso Ocidental, assim parece, não apenas de que precisamos ter um corpo para ter um sexo, mas precisamos ter um sexo para se ter um corpo (Moore, 1994, p. 14). Sexo, nos termos da construção filosófica Ocidental, é algo que diferencia os corpos. Ter/ ser um corpo parece ser a característica mais importante da pessoa, aquela que constitui sua identidade (Moore, 1994, p. 36).

Como aponta Strathern, pelo meio de nossa concepção de propriedade, acreditamos que itens individuais estão ligados a proprietários individuais: a propriedade é construída como uma relação entre pessoas e coisas, a pessoa é a entidade a qual as coisas são externas (Strathern, 1988, p. 104). A identidade de gênero é uma posse deste tipo (Haraway, 2004, p. 220), ela é tida como uma parte de propriedade ligada à pessoa (Strathern, 1988, p. 105). As pessoas possuiriam suas mentes assim como seus corpos, e suas mentes as tornariam proprietárias de suas ações e também autora delas (Strathern, 1988, p. 35). Assim vemos o indivíduo como tendo um corpo sexuado dado (masculino ou feminino), que possui vontades próprias, independentes, individuais e autônomas, vontades que muitas vezes manifestariam seus interesses contra o peso da tradição e do costume. A ideia que temos de 'sociedade' considera que a ação coletiva vincula entidades diferentes de si. A socialidade é vista repousar em relações entre indivíduos, em construções sociais do indivíduo, ou de pessoas sexuadas, cuja individualidade ou atributos sexuais estão para além dessa construção (Strathern, 1988, p. 94). O poder da sociedade seria controlar o indivíduo. 
Nesse sentido, subordinar a 'natureza' ou socializar o 'indivíduo' são imagens uma da outra (Strathern, 1988, p. 94). A sociedade seria a única fonte de humanidade do indivíduo, é por meio dela que ele/a transcende a vida orgânica, que seria sua condição natural.

Às dicotomias natureza e cultura, indivíduo e sociedade, se sobrepõe uma terceira: a dicotomia público e doméstico; que já foi mencionada e retoma-se aqui. Na sociedade Ocidental, a família, a casa, e o 'doméstico' se fundem em uma única unidade, definida em oposição à esfera 'pública' do trabalho, negócios e política (Moore, 1988, p. 23; Rapp, 1979, p. 510). Relações comerciais envolvem relações de competição, negociação e contrato que a sociedade Ocidental vê como separadas e em oposição às relações de intimidade, criação e cuidado associadas à família e ao lar (Moore, 1988; Rapp, 1979). A esfera pública, o lugar do trabalho, deve se afastar o máximo possível da infantilidade do lar, para se tornar um adulto é preciso sair do circulo doméstico (Strathern, 1988, p. 89). As mulheres Ocidentais correm o risco de aparecerem menos como pessoas sociais; seja porque suas criatividades são entendidas como naturais ao invés de culturais (dadas em suas capacidades de 'ter filhos'), ou então porque elas pertenceriam ao mundo mais estreito do grupo doméstico ao invés do mundo social mais abrangente dos negócios públicos (Strathern, 1988, p. 89).

$\mathrm{Na}$ antropologia, se em um primeiro momento o grupo doméstico foi definido como a família nuclear composta de um pai, uma mãe e os filhos do 'casal' - assim como Malinowski definiu a família (Yanagisako, 1979 apud Moore, 1988, p. 24); em seguida, os laços foram minimizados e foi argumentado que a unidade social básica da sociedade não seria a família, mas sim a unidade mãe-filhos (Fortes; Goodenough apud Moore, 1988, p. 23-4), como se vê em Rosaldo (1974). Nessa formulação, a própria noção de 'doméstico' se constrói entrelaçando os conceitos de 'mãe' e 'cuidados maternos' (Moore, 1988, p. 25). A categoria 'mulher' está diretamente associada com atributos maternos como fertilidade, naturalidade, amor materno, cuidado, alimentação, dar a vida e reprodução (Moore, 1988, p. 25). Na sociedade ocidental, as categorias 'mulher' e 'mãe' se sobrepõem, o resultado disso é que a definição de 'mulher' depende do conceito de 'mãe' e das atividades associadas ao 'ser mãe' (Moore, 1988, p. 25) . E assim, é 
possível ver que um dos pressupostos do conceito Ocidental de gênero é insistir que a maternidade é natural e a paternidade cultural, que as mães fazem os bebês naturalmente, biologicamente (Haraway, 2004, p. 220). A paternidade seria variável nas diversas culturas, enquanto a maternidade seria mais natural, mais universal e mais constante (Moore, 1988, p. 24).

No parentesco 'euro-americano' (Ocidental), os relacionamentos íntimos estão vinculados à procriação, e a procriação está diretamente relacionada ao intercurso sexual, à concepção e ao parto (Strathern, 1995, p. 303; Schneider, 1968). O intercurso sexual reproduz a parentalidade como o resultado dessa união de partes que se diferenciam pelo gênero: uma mulher e um homem tecem relações sexuais para terem uma criança. Mas se por um lado pais e mães são vistos como iguais em termos de doação genética, seus papéis no processo do parentesco são diferentes. A maternidade se estabelece com a mãe dando à luz, enquanto a paternidade se faz pela prova de relações sexuais com a mãe (Strathern, 1995, p. 303; Schneider, 1968). É convenção cultural imaginar que o pai jamais pode "saber" na verdade que o filho de uma mulher é também seu - isso tem sempre de ser provado (Strathem, 1995, p. 311).

Se no Ocidente se afirma que a procriação deve ocorrer no contexto de um relacionamento, imagina-se que o parceiro social seja também um parceiro biológico (Strathern, 1995, p. 314). Mas como a procriação é tida como um fato natural, deposita-se na mulher, tanto a naturalidade de seu papel como mãe, dado; como a responsabilidade de fornecer um pai aos 'seus' filhos por meio do relacionamento com o homem com quem mantém relações sexuais. Deposita-se nas mulheres a imagem de guardiãs do ideal que a procriação biológica deve estar vinculada a um relacionamento social ( Strathern, 1995, p. 314-315). Supõe-se que os relacionamentos devem ser criados, construídos por obra humana sobre um mundo natural, dado, de indivíduos cujos corpos determinam sua diferença sexual (Strathern, 1995, p. 317). Assim, nossa ideia de procriação talvez seja a metáfora mais poderosa para a forma como concebemos as relações de gênero.

O encadeamento dos argumentos exposto aqui é uma imagem de como pensamos a nós mesmos/as. Não se trata exatamente de afirmar que todas as sociedades ditas Ocidentais são assim. Trata-se, 
sobretudo, de apontar para as descrições que fazemos da forma como vivemos juntos/as. Essas descrições se constroem por meio de certas imagens como corpos sexuados, indivíduo, sociedade, natureza, cultura, esfera doméstica, esfera pública e é claro, homem e mulher: essas são algumas de nossas ficções (Strathern, 1988, Haraway, 2004). Mas, como também sabemos, são igualmente a forma como acabamos por descrever outras culturas. Nesse sentido, é preciso estar consciente da forma como nosso próprio pensamento se formula para que se esteja consciente de nossos interesses nas descrições que fazemos - por exemplo, o interesse dos/as antropólogos Ocidentais na análise de outras sociedades (Strathern, 1988, p. 16). E é aqui que o debate feminista contemporâneo surge colocando problemas para a antropologia, e para nossas autodescrições - e, consequentemente, para as descrições que fazemos de outros povos.

\section{Feminismos e Diferença}

Em meados dos anos de 1980, o binarismo sexo/gênero, tão importante para o nascimento e fortalecimento do feminismo, começou a ser fortemente questionado e criticado por movimentos feministas outros que os movimentos liberais-socialistas de mulheres 'brancas', de classe média, heterossexuais. As reivindicações se baseiam ${ }^{6}$, sobretudo, no conceito de 'diferença', tema não apenas ausente da 'segunda onda', mas também deliberadamente excluído da discussão em procura de uma luta universal das mulheres contra a submissão (também dita universal) das mulheres. Feministas que se veem como pertencendo a outras realidades acusam e contrapõem as feministas 'euro-americanas', apontando para o racismo e o pensamento colonial implícito em suas reinvindicações (Haraway, 2004, p. 222). A universalidade do sistema sexo-gênero e a ruptura analítica entre o público e o privado foram politicamente criticadas por mulheres que não se identificavam com as questões colocadas por essas dicotomias. Um dos principais argumentos é que a categoria Ocidental de gênero quando utilizada para caracterizar mulheres 'homossexuais', mulheres 'não brancas', mulheres 'do Terceiro Mundo' frequentemente resulta na reprodução do discurso orientalista, racista e colonialista (Haraway, 2004, p. 237). 
A controvérsia e as acusações passaram então a ser parte da forma como o movimento feminista se constitui como movimentos múltiplos, sem voz única, em contraponto. Na qual a reinvenção, o questionamento, quer dizer, a posição parcial é a forma como as pesquisadoras feministas se autodefinem. No entanto, essa forma de dialogar "[...] com compatibilidade sem comparabilidade [...]" (Strathern, 2004, p. 38 ) não foi alcançada sem confronto.

As mulheres 'brancas' foram levadas a perceber que as formas como elas colocavam suas "irmãs" de outras classes sociais, de outras orientações sexuais, de outros países, não brancas, era muito parecido com a maneira que os homens tratavam elas ${ }^{7}$. Talvez o maior problema tenha sido o fato de elas considerarem 'mulheres' como um grupo já constituído, coerente com interesses idênticos sem levar em conta a classe e as contradições étnicas ou raciais (Mohanty, 1984, p. 337).

O discurso feminista Ocidental ao supor mulheres como um grupo coerente, já constituído, o qual é posto no parentesco, nas estruturais legais ou outras, define as mulheres do Terceiro Mundo como sujeitos fora destas relações sociais, ao invés de olhar como as mulheres são constituídas através destas estruturas. (Mohanty, 1984, p. 351, tradução livre, grifos da autora)

A grande deficiência do feminismo 'social-marxista' ao definir suas reivindicações foi supor que todas as mulheres possuem os mesmos problemas e de utilizar a imagem da 'mulher branca' como universal.

A imagem de mulher que foi reivindicada pelos movimentos da 'segunda onda' é a mulher laica, liberada, sob controle de sua vida e de seu corpo. Essa é uma autorrepresentação, e não necessariamente uma realidade material (Mohanty, 1984, p. 353). Porém, essa autoimagem se constrói também em oposição às mulheres 'não brancas' e do 'Terceiro Mundo' (mulheres virgens, mulheres que usam véu, etc.) (Mohanty, 1984, p. 353), cujas práticas culturais são vistas como uma espécie de 'relíquia feudal' (Amos; Parmar, 1984, p. 7). A ideia de que mulheres do mundo inteiro poderiam (e deveriam) se libertar das práticas 'opressoras' de suas culturas, subentende que a mulher 'branca', 'Ocidental' é um modelo do que deveria ser a mulher 'livre'/'não submissa' e que esta teria algo a ensinar às outras mulheres, presas na 'tradição'. Mas muito 
cedo foi apontado o fato de que os ganhos das mulheres 'brancas' se dão a custa das mulheres 'não brancas' (Amos; Parmar, 1984, p. 5), tanto na 'esfera local' dos países, como na 'esfera global' das relações entre países. Como coloca Audre Lorde (1981, p. 96, tradução livre):

Como vocês lidam com o fato de que as mulheres que limpam suas casas e cuidam de seus filhos enquanto vocês frequentam conferências em teoria feminista são, na maioria das vezes, mulheres pobres e mulheres 'negras'? Qual a teoria por trás do feminismo racista?

O movimento das mulheres 'brancas', Ocidentais, de classe média, heterossexuais, além de ter sido acusado de racista e colonialista, foi também criticado por sua incompetência (ou falta de vontade) em lidar com a diferença. As reivindicações do movimento foram severamente criticadas. Por exemplo, duas das principais frentes de combate, a família e a sexualidade, começaram a se mostrar radicalmente diversa em outras realidades. A sexualidade, que para as mulheres 'brancas' é central - tanto a 'liberdade' sexual em ter o(s) parceiro(s) que se deseja como na 'escolha' da maternidade, por exemplo -, tem um papel bastante secundário na luta para a autodeterminação e contra o imperialismo das mulheres 'Negras' ou do 'Terceiro Mundo' (Amos; Parmar, 1984, p. 12).

Nas mesmas linhas, a família como a fonte de opressão das mulheres, o 'direito' ao divórcio e ao trabalho, se mostram distante daquilo que vivenciam as mulheres Afrodescendentes, por exemplo. Como argumenta Patricia Hill Collins, o modelo ao qual muitas acadêmicas feministas lutavam contra - a mulher dedicada à esfera doméstica e ao cuidado com os filhos e excluída da vida pública - não se aplica às mulheres african-americans (e tampouco às afrobrasileiras): durante a escravidão, as mulheres Afrodescendentes trabalhavam, como os homens, sem serem pagas nas plantações e tinham a privacidade de suas famílias constantemente violadas; nos dias atuais essas mulheres devem trabalhar fora de casa - muitas vezes em trabalhos mal remunerados - e seus trabalhos as afastam de seus filhos $^{8}$ (Collins, 2000, p. 47). Segundo a autora, ao invés de considerar o trabalho e os padrões de família das mulheres Negras como desviando 
da normalidade do ideal da família tradicional, uma abordagem mais frutífera seria desafiar os próprios construtos do trabalho e da família eles mesmos (Collins, 2000, p. 47). O trabalho fora de casa e a falta de oportunidade e tempo para cuidar dos filhos, se tornaram a realidade de muitas mulheres não brancas, pertencendo a minorias, como mostra também Anzaldúa (1987, p. 10) para as mulheres México-americanas (autodenominadas Chicanas).

No Brasil, a expressão "matriarcado da miséria"” foi usada para

[...] designar a experiência histórica das mulheres negras brasileiras na sociedade brasileira marcada pela exclusão, discriminação e rejeição social e a despeito dessas condições, o seu papel de resistência e liderança de suas comunidades miseráveis. (Carneiro, 2000, p. 5)

O feminismo negro brasileiro aponta de forma crítica para as desigualdades raciais as quais padecem as mulheres afro-brasileiras (Carneiro, 2003, p. 121), desigualdades que só podem ser transformadas através do combate ao racismo, a prioridade politica das mulheres negras (Gonzalez apud Carneiro, 2003, p. 119). Assim como nos Estados Unidos, na Grã-Bretanha e em outros lugares, a ação política das mulheres negras no Brasil introduziu uma crítica fundamental às concepções do feminismo branco ${ }^{10}$.

Ainda na questão das famílias, as formas alternativas de conceber o parentesco e os vínculos que constroem relações foram dificilmente assimiladas pelas mulheres 'brancas':

[...] a histeria dos movimentos das mulheres Ocidentais em torno de temas como casamentos arranjados, o purdah, famílias encabeçadas por mulheres, está quase sempre além da compreensão das mulheres Negras - e muito vinculada às chamadas noções feministas daquilo que constitui boas ou más práticas em nossas comunidades na Grã-Bretanha ou no Terceiro Mundo. (Amos; Parmar, 1984, p. 11, tradução livre)

Argumenta-se que ao considerar a família como uma fonte de opressão para as mulheres, as feministas 'brancas' revelam uma "miopia cultural e racial" (Amos; Parmar, 1984, p. 15) - que acaba por prejudicar as outras mulheres, por exemplo, ao influenciar as políticas públicas 
para a legislação na área de imigração ${ }^{11}$ (na Inglaterra) (Amos; Parmar, 1984, p. 15).

A possibilidade de diferença que as mulheres 'brancas' conseguiam conceber até outras mulheres terem voz no discurso feminista era uma diferença que não ousava questionar a fundação de suas próprias existências e fazeres (Trinh, 1987, p. 14). O que o feminismo radical de mulheres 'não brancas' trouxe foi a desestabilização dos cânones do feminismo Ocidental: "o léxico da reprodução, do desejo, da nominação, da maternidade, da paternidade, etc., é lançado numa profunda crise" (Haraway, 2004, p. 241). A diferença entre as experiências das mulheres se torna então a base na qual se constitui a 'terceira onda feminista', ou 'a teoria feminista multicultural' (Haraway, 2004, p. 227). Uma diferença corporificada, que parte das experiências vividas, personificadas, incorporadas. Emerge uma politica da diferença (Haraway, 2004, p. 244), no qual o que está em pauta não é o relativismo, as diversas formas de 'se tornar mulher', mas sim uma reconstrução de conceitos de subjetividade social e as práticas de escrita a ela associada (Haraway, 2004, p. 244). A interseccionalidade social, cultural e política, passa a ser a forma privilegiada para se falar de gênero. No entanto, é preciso lembrar o fato, já mencionado, que o movimento feminista contemporâneo é constituído por sua multiplicidade, existem mulheres que defendem questões relacionadas à "segunda onda", outras que estão mais preocupadas com questões colocadas pela "terceira onda". Os 'confrontos', 'desacordos' e 'tensões' do movimento é o que proporciona sua criatividade e força.

O conceito de 'corpo', e de personificação/ corporificação (embodiement) sempre foi uma preocupação central para as teorias feministas. Na 'terceira onda', ele começa a ser rigorosamente repensado.

O corpo, a mais visível diferença entre homem e mulher, o único que oferece um terreno garantido para aqueles/as que procuram o permanente, a 'natureza' e 'essência' feminina, continua assim a base mais segura para ideologias racistas e sexistas. (Trinh, 1987, p. 18, tradução livre)

Os conceitos feministas do "sexo" determinado pela biologia e do "gênero" como a diferença localizada social e historicamente, são postos em cheque, e com eles "[...] o poder analítico no interior de uma 
tradição Ocidental especifica" (Haraway, 1995, p. 35). Questiona-se a ideia do corpo como "[...] página em branco para inscrições sociais, inclusive aquelas do discurso biológico" (Haraway, 1995, p. 35 ).

Esse questionamento surge como consequência das tensões postas pelos feminismos não brancos, não burgueses, não heterossexuais, não Ocidentais e outros, e abre espaço para a critica à divisão sexo/ gênero, ela mesma reflexo da dicotomia natureza/cultura. Autoras como Judith Butler (1999) e Donna Haraway (1995) formulam a implosão da divisão sexo e gênero reivindicando, em linhas gerais, que as categorias homem/mulher não podem ser dadas a priori, que o "sexo" também é socialmente construído além de ser uma ferramenta política. Mais recentemente, Paul Beatriz Preciado (2015) vem aprofundando e inovando essa forma de raciocínio com o conceito de contrassexualidade. Esses argumentos vão para a mesma direção da pesquisa da bióloga Anne Fausto-Sterling (1993) sobre pessoas intersexuais, que afirma existir cinco sexos e não dois, como se costuma pensar - uma crítica ao binarismo inerente em nossa maneira de pensar.

O que está em jogo na discussão feminista sobre diferença são os próprios construtos analíticos da sociedade Ocidental. O conhecimento feminista da 'terceira onda' aponta para o fato de que o pensamento 'burguês' se formula de forma conservadora, e em seguida universaliza seus pressupostos como se eles fossem válidos para tudo e todos. Essa é uma crítica também à antropologia, crítica colocada de maneira parecida por pensadores/as pós-coloniais. A forma como a antropologia objetifica o conhecimento, acomoda um modo de vida e uma racionalidade do mundo dominada pelo poder Ocidental (Asad, 1973, p. 17).

Mas eis que a antropologia não teve outra opção a não ser a de se repensar depois das críticas formuladas tanto pelos movimentos feministas como por pesquisadores/as que chamamos de "pós-modernos/ as" e "pós-coloniais". Atualmente, a disciplina busca produzir um conhecimento 'reverso' ou 'simétrico', uma antropologia que considera a sociedade dos antropólogos como necessitando ser descrita e estudada tanto quanto qualquer outra. Outra tarefa importante é a de mostrar que nossos conceitos - como 'mulher', 'corpo', 'sexo' e 'gênero', por exemplo - ao serem estudados em diferentes coletivos humanos, colocam problemas que afetam estes mesmos conceitos tal como eles 
são concebidos por nós. A última parte deste artigo procurará apresentar três etnografias regionais que fazem 'mulher', 'corpo', 'gênero', querer dizer outra coisa e desafiam assim nossas categorias de entendimento, inclusive a própria forma como as teorias feministas são formuladas.

\section{Três Narrativas Etnográficas sobre 'Corpo'}

Nesta parte final do artigo procura-se abordar o tema da 'pessoa' e do 'corpo' - e a ideia de 'corpo sexuado' subjacente a esses termos - pensando a teoria antropológica em diálogo com três discussões etnográficas específicas: a Melanésia, a partir da autora Marylin Strathern; o Egito, a partir da autora Saba Mahmood; e a Amazônia a partir do meu próprio trabalho em diálogo com a teoria antropológica amazônica. As etnografias que proponho discutir serão tratadas de um modo que eu qualificaria de 'ilustrativo' - e não em todas as suas complexidades. A ideia é apenas apontar para o fato de que existem outras 'criatividades' (Wagner, 1981) diferentes da Ocidental para se pensar temas como corpo e pessoa. Nesse sentido, a antropologia e as teorias que surgem da etnografia aparecem também como uma contraposição à forma naturalizada que se coloca o problema de corpo e pessoa - e como tentativas de tensionarem nossas categorias e nossas formas de pensar. Não gostaria de dar a impressão de estar reiterando a famosa oposição "Nós" e "Eles", com a qual a antropologia vem se debatendo já há algum tempo. Minha ideia é mais a de apresentar outras formas de autodescrição, tão poderosas quanto a nossa, e que nos fazem então, refletir sobre a nossa - para talvez chegarmos a lugares muito próximos às críticas colocadas pelo movimento feminista "da terceira onda", também conhecido como pós-feminismo, mencionado na parte anterior.

\subsection{Melanésia}

Vou começar esta parte mencionando como os "rituais" de iniciação masculina foram descritos na Papua Nova Guiné durante as décadas de 1950 e 1960, e argumentando sobre as objeções realizadas por Marylin Strathern a este debate, sobretudo em seu livro “O gênero da 
dádiva". No contexto etnográfico da Papua Nova Guiné, esses 'rituais' foram interpretados em termos de 'processos de socialização', onde os meninos eram 'socializados na sociedade' (Strathern, 1996, p. 72). Grosso modo, eles foram explicados como formas para os homens controlarem a sociedade, e um mecanismo de passagem da natureza para cultura (Strathern, 1988, p. 3). Os ritos foram pensados como uma maneira para construir homens, em oposição à 'mulheres naturais' (Strathern, 1988, p. 100), cuja função era a de coesão social. E, assim, os indivíduos eram vistos como recrutados em seu sexo ao invés de recrutados como membros de grupos.

Um dos pressupostos por trás de tal processo de análise seria que a identidade se constitui pela posse de qualidade exclusiva a cada sexo (Strathern, 1988, p. 64). E a pergunta que Strathern formula é se um indivíduo teria realmente certas características capazes de torná-lo inequivocamente masculino (Strathern, 1988, p. 64-65). E sua resposta é não: em Hagen são as relações que são femininas ou masculinas, não as pessoas. A autora demonstra que as práticas de iniciação são formas pelas quais as pessoas mostram a si mesmas o fato de que elas podem extrair de (outras) pessoas a capacidade de criar relações (Strathern, 1996, p. 72). Os ritos construiriam maneiras de saber quais são as capacidades do corpo (Strathern, 1988, p. 103). As evidências dessas capacidades repousam em uma eficácia da ação, que implica, no caso melanésio, em relação (Strathern, 1988, p. 123). O efeito desejado dos ritos seria o de trazer consciência para o corpo (Strathern, 1988, p. 131), saber que o corpo é feito de relações que precisam ser mantidas, destruídas, criadas incessantemente.

As pessoas na Melanésia seriam concebidas dividualmente e individualmente; e tudo se passa como elas contivessem uma socialidade generalizada dentro delas. As pessoas aqui seriam construídas como compostas das relações que as produzem. Em outras palavras, pessoas singulares podem ser imaginadas como um microcosmo social (Strathern, 1988, p. 13). Para a autora, um dos mais conhecidos axiomas da Melanésia é o de que as aparências enganam, e de que a identidade unitária contém dentro de si outras identidades (Strathern, 1988, p. 122). Em termos de gênero, uma figura de um único sexo terá partes 
'pertencendo' ao sexo oposto, estas são imaginadas como contidas (ou encompassadas) dentro do corpo individual (Strathern, 1988, p. 122). Um corpo masculino encompassa partes femininas, e inversamente. O 'corpo corpóreo' é apresentado como exclusivamente feminino ou masculino para efeitos rituais específicos, as pessoas não são concebidas como tendo um único sexo (Strathern, 1988, p. 122). Existiriam dois modos de constituição de gênero: o homorfismo (homorphism) entre as pessoas, ou entre suas partes constituintes, produz relações do mesmo-sexo (same-sex); enquanto o dimorfismo produz relações de sexos-cruzados (cross-sex) (Strathern, 1988, p. 122). Reivindicações de masculinidade total (all-maleness) ou feminilidade total (all-femaleness) seriam apenas transitórias e definições temporárias do poder (Strathern, 1988, p. 123).

Se a pessoa individual é o local no qual as interações com outros é registrado, então é possível supor uma imagem das relações sendo como troca de partes (da pessoa). De forma resumida, na Melanésia as relações sociais tomariam a forma conhecida na literatura antropológica como troca de dom (Strathern, 1988, p. 132), algo como as pessoas trocam partes de si mesmas, ou compõem partes de si mesma, ao se relacionarem com outras. Nesse sentido, 'corpo', 'sexo', 'pessoa' não são algo dado a priori, mas sim efeitos de relações. A importância das relações na composição da pessoa melanésia pode também ser vista por meio dos escritos sobre os Grandes-Homens (Big Men). Esses homens estão presentes em relatos etnográficos pelo menos desde a época de Malinowski: eram eles que trocavam, no Kula, colares feitos de conchas vermelhas, chamados soulava, e os braceletes feitos de conchas brancas, os mwali.

Marylin Strathern revisita o Kula, e aponta para o fato de os grandes chefes seriam aquelas pessoas capazes de encompassar mais relações do que as demais pessoas, e isso seria o meio pelo qual eles adquirem prestígio. No entanto, isso não faz com que as mulheres sejam vistas como 'menos' do que os homens ou menos que os GrandesHomens, o que apenas evidencia a ideia de que a domesticidade feminina simboliza em Hagen negócios opostos aos interesses coletivos dos homens (Strathern, 1988, p. 89). Se é verdade que a produção, o 
trabalho, é desvalorizado com relação às atividades em torno da troca cerimonial, que são atividades que levam ao prestígio (Strathern, 1988, p. 91), isso não significa que o estatuto das mulheres como pessoas sociais seja menor (Strathern, 1988, p. 89). Os negócios dos homens e suas buscas pelo prestígio também lembra a eles que entanto que homens eles devem ser eficazes em suas obrigações domésticas (Strathern, 1988, p. 91). Antes de tudo, a casa/lar é o lugar onde as pessoas se mostram pessoas respeitáveis (proper), comprometidas em transações recíprocas: é a esfera doméstica que produziria pessoas inteiras (Strathern, 1988, p. 92).

\subsection{Egito}

Sigamos agora para o Egito, onde a discussão de Saba Mahmood segue as mesmas linhas de Strathern e Wagner, argumentando que não são todas as sociedades que pensam o indivíduo, a pessoa, o corpo, em oposição, e em luta contra a sociedade. Saba Mahmood é etnógrafa do movimento urbano de mulheres em mesquitas na cidade do Cairo, e afirma que para essas mulheres, algo que elas identificam como docilidade é uma forma de agência que não conota sentido de passividade, mas sim de luta, esforço, empenho e conquista (Mahmood, 2001, p. 210). As questões de Mahmood também abordam temas como 'religiosidade e disciplina', 'secularidade', 'mundo muçulmano', 'pós-colonialismo', mas um de seus diálogos mais importantes é com as ideias liberais-feministas. Para a autora, o tenso relacionamento entre feminismo e religiosidade deve-se às relações históricas entre sociedades Islâmicas e o chamado Ocidente, mas também aos desafios que os movimentos islâmicos contemporâneos colocam para as politicas secular-liberais, cujo feminismo fez parte integral (Mahmood, 2001, p. 202). Segundo o conhecimento feminista 'liberal, secular', a agência humana é aquela que procura autonomia politica e moral dos sujeitos face ao poder (Mahmood, 2001, p. 203).

Existiria assim (no liberalismo) a ideia de autonomia do indivíduo e a vontade deste de realizar seus próprios interesses contra o peso da tradição e do costume. Além disso, as mulheres seriam vistas como 
marginais, subordinadas e oprimidas em todas as culturas. A autora estuda o movimento da'wa, que faz parte do 'renascimento Islâmico' presente no Mundo muçulmano, incluindo o Egito, desde 1970 (Mahmood, 2001, p. 202). Nele, virtudes religiosas são consideradas importantes, e uma delas, particularmente importante para as mulheres, é a de modéstia e timidez: al-hayã'. Praticar al-haya á significa ser modesta e capaz de sentir e agir timidez (Mahmood, 2001, p. 213). Quando a autora fala em "agir em timidez", ela aponta para a ideia de que a timidez seria mais uma ação do que uma propriedade, ela seria um movimento. Essa forma de conceber tiraria a timidez da esfera das representações e a colocaria na esfera da ação. As práticas de timidez e o uso do véu revelam que o que está em jogo não é o regulamento do corpo feminino por autoridades religiosas masculinas, mas o próprio conceito pelo qual o corpo e a mente estão articulados para modelar uma pessoa tida como disciplinada (Mahmood, 2001, p. 217). Usar o véu serve como meio para ensinar a si mesma os atributos da timidez, mas, ao mesmo tempo, faz parte integral da prática da timidez (Mahmood, 2001, p. 203). O véu seria assim uma forma de ser e se tornar um tipo de pessoa (Mahmood, 2001, p. 215).

O corpo é uma parte essencial do argumento da autora:

[...] (no movimento da'wa existe) toda uma conceitualização sobre o papel do corpo na produção do eu (self) em que a atitude externa do corpo constitui tanto a potencialidade, como o meio, através do qual uma interioridade se realiza. (Mahmood, 2001, p. 214, tradução livre)

Apesar de associarmos docilidade com o abandono da agência, o termo literalmente implica uma maleabilidade necessária para alguém ser instruído em um conhecimento particular - um significado que carrega menos um senso de passividade e mais um senso de luta, esforço, e conquista, aquilo que Mahmood chama de agência dócil (Mahmood, 2001, p. 210). A docilidade aponta para formas específicas que uma determinada mulher realiza certo número de operações em seus pensamentos, corpo, conduta e forma de ser, para atingir um estado de 'felicidade', 'pureza', 'sabedoria', 'perfeição' de acordo com uma tradição discursiva particular (Mahmood, 2001, p. 210). 
A etnografia de Mahmood dá destaque também a ideia de piedade. Apesar da 'piedade' (piety) poder ser atingida através de práticas que são devocionais assim como mundanas, ela requer mais do que uma performance das ações (Mahmood, 2001, p. 212). A 'piedade' acarreta, como a 'timidez', a apropriação de disposições através da simultaneidade de um treino do corpo, emoções e razão. As virtudes religiosas devem adquirir o estatuto de hábitos personificados/ incorporados, embodied (Mahmood, 2001, p. 212).

Aqui, a agência, essa agência dócil nos termos de Mahmood, não seria um sinônimo para resistência a relações de dominação. Mahmood resume seu argumento dizendo que se o conhecimento acadêmico deseja ser algo mais que o exercício de denuncia ou julgamento, ele terá que pensar para além de suas concepções naturalizadas (Mahmood, 2012 , p. xii). Os termos que as pessoas utilizam para organizar suas vidas não são glossários sobre pressupostos universalmente divididos sobre o mundo e o lugar das pessoas nele. Mas são constitutivos de formas diferentes de pessoa, conhecimento, experiência, personificação, corporalidade. Assim chego a última parte: a Amazônia indígena.

\subsection{Amazônia}

Os estudos consagrados às Terras Baixas da América do Sul demonstraram desde cedo que, nessas sociedades, a forma humana do corpo deve ser produzida e que essa produção é um processo contínuo em que a alimentação e a ornamentação possuem um papel central na fabricação de 'pessoas de verdade'. Com a teoria do perspectivismo (Viveiros de Castro, 1996; Lima, 1996), o corpo adquiriu uma nova dimensão nas análises, sendo ele aqui o próprio centro do ponto de vista sobre o mundo. Se o corpo deve ser fabricado, é porque o ser humano depende da forma como as pessoas se alimentam, daquilo que comem, com quem comem, de quem cuida delas. Essa 'consubstancialidade' é algo que se reconhece por seus efeitos, efeitos visíveis nas pessoas envolvidas, em seus corpos (Coelho de Souza, 2004).

O grande problema para boa parte das sociedades indígenas é que a "alma" é 'destacável', por assim dizer, do corpo, e isso dá instabilidade 
para o corpo. Essa instabilidade se deve ao fato que possuir uma 'alma' implica na capacidade em se transformar: virar outro tipo de pessoa, um tipo de gente, ver por outra perspectiva (Lima, 1996). Por isso, saber controlar as possíveis metamorfoses corporais, que acontecem devido às relações tecidas pela 'alma', é essencial nessas sociedades ${ }^{12}$.

Davi Kopenawa, no livro "A queda do céu", escrito em parceria com Bruce Albert, fala de sua experiência como xamã. Essa experiência está vinculada ao viajar e conhecer o mundo dos xapiri - que seriam 'almas', espectros, seres celestes: lindos, brilhantes, o ideal de beleza e da humanidade, mas também seres perigosos para os humanos. Ele fala que para fazer essas viagens, ele mesmo deve "se tornar espectro", "se tornar xapiri" (Kopenawa; Albert, 2010, p. 368), por meio de duas formas: pela ingestão nasal da substância alucinógena yãkoana, e por meio do sonho (Kopenawa; Albert, 2010, p. 52). Se essas são as formas privilegiadas para 'se tornar espectro', ao longo do livro, Davi indica também outras maneiras, mais involuntárias, em que isso pode acontecer a qualquer pessoa, não apenas aos xamãs ${ }^{13}$. Nessas circunstâncias, teríamos aquilo que os/as antropólogos/as chamam de separação entre alma e corpo, e que Davi chama de "se tornar espectro". A experiência que a alma vivência é a experiência de viajar. Para Davi, sonhar, se tornar espectro, é a forma de conhecimento por excelência; uma forma privilegiada de conhecer/saber/aprender (Kopenawa; Albert, 2010, p. 502). Nesse aprendizado, os xapiri, os seres celestes, "almas", espectros, são os professores.

Eu gostaria assim de entrar na minha pesquisa, em andamento, sobre o que poderia ser chamado de um 'ritual de iniciação feminina', mas que eu prefiro chamar de "festa"14. A partir de minha etnografia com os Jarawara, povo falante de uma língua Arawá e habitantes do médio curso do rio Purus, venho procurado refletir sobre a festa de saída das meninas em reclusão, o mariná, e seus efeitos na composição de uma agência feminina que de acordo com a teoria jarawara seria algo que podemos traduzir por "levável" (towakama). Muitas das hipóteses que se apresenta aqui estão baseadas na experiência que eu tive em um mariná especifico, o mariná de Dyimamirira, e nos deslumbres ( Strathern) desestruturantes que vivi nessa ocasião. 
Assim que a Dyimamirira menstruou pela primeira vez, sua 'mãe' e 'tias' fizeram para ela um uma pequena casinha, chamada wawasa, construída no interior da casa familiar. Ela ficou reclusa nesse compartimento durante aproximadamente quatro meses, saindo apenas uma vez por dia para tomar banho. Ao contrário do que poderíamos imaginar, nesses meses que precederam a festa, Dyimamirira não descansou, ao contrário, ela ficou exausta. Durante o dia, ela sentia diversos desconfortos, devido, sobretudo, ao calor no interior do wawasa, completamente fechado e com apenas uma pequena passagem que serve de porta. À noite, ela mal dormia porque tinha muito medo, medo de 'alma', de inamati. Inúmeras vezes, ela acordou sua mãe Makeni durante a noite, e acabou indo dormir em sua rede. Quando chegou o momento da festa, Dyimamirira estava já muito cansada. Isso foi encenado, por assim dizer, no primeiro dia das danças noturnas, quando a Dyimamirira saiu do wawasa foi vestida por suas 'tias' (amise) e 'irmãs' (ati/asima) com a roupa da festa, e ela não conseguia ficar de pé, estava cansada, precisou de uma cadeira. Eu fiquei um pouco tensa, mas rapidamente me foi dito que era normal aquilo tudo, 'que ela estava cansada'.

Durante os três dias de festividade, Dyimamirira praticamente nunca ficou sozinha, tranquila. De dia, as mulheres cantavam os cantos chamados eé ao lado de seu wawasa das $7 \mathrm{~h}$ às $17 \mathrm{~h}$. Depois, ela era levada para tomar banho, voltava, recebia visitas dentro do wawasa, jantava, recebia mais visitas e, então, passava a noite inteira no 'pátio' da aldeia dançando e cantando, com outras pessoas. De manhã, os cantos eé recomeçavam, e assim se passaram três dias e três noites. Acredita-se que as 'ações rituais' configuravam situações em que Dyimamirira dormia pouco, o que significa que ela podia dormir a qualquer momento. Uma situação que visaria um corpo um tanto 'cansado', um tanto 'dormente', um tanto 'leve': leve não no sentido de não pesado, mas sim no sentido de "levável" (towaka), "carregável" (weye). Um corpo que fique em um estado de sonolência e, ao sonhar, viaje.

Como vimos, no mundo ameríndio, a 'alma' pode se separar do corpo e viver experiências. Não poderei desenvolver em detalhes aqui, mas me parece que na festa de saída das meninas Jarawara, o efeito que se deseja é que ela aprenda a sonhar e a viajar, que ela aprenda 
que sua alma é capaz de viajar para conhecer outros tempos-espaços e, assim, adquirir conhecimento. E isso seria proporcionado pela falta de sono, por algo que poderia se aproximar a uma subjetivação onírica. Isso me leva para a ideia de que a "sonolência" (nokobisa), o "cansaço" (mama) e a "beleza" (amosa) são formas de ações rituais que visam extrair dos corpos femininos suas capacidades de "serem leváveis" (towakama). Algo que simetrizaria com suas "almas viajantes", efeitos da festa de iniciação. Outro tipo de pessoa também "carregável" (weye), "levável" (towaka) no mundo Jarawara são os xamãs, que viajam - após o consumo de rapé - para outros tempos-espaços nas costas de seus 'filhos-planta' (Maizza 2014), que poderiam ser chamados de 'espíritosauxiliares'. Nessas viagens, os 'filhos-planta' do xamã, que moram no neme (algo como uma 'camada superior'), descem à Terra 'voando', colocam o xamã nas suas costas, e o levam para outros lugares, onde ele conhece e tece relações com diversos tipos de seres, sobretudo os inamati ('almas', 'espíritos de plantas', sobretudo).

Sugere-se aqui a ideia de uma 'agência feminina levável', o que mostra que ao contrário do que poderíamos pensar se acionássemos a ideia de 'mulher' e 'crianças' como 'unidade básica do grupo doméstico', as mulheres jarawara não estão necessariamente relacionadas à esfera doméstica da sociedade, à criação de filhos e cuidados cotidiano com a alimentação. Mas sim, e provavelmente, elas estão vinculadas a sabedoria dos xamãs, que se deslocam em tempos-espaços alheios para conhecerem o mundo, os mundos.

Mais uma vez, o que parece estar em jogo é uma noção de pessoa vinculada à produção de corpos e à corporalidades específicas. O que venho tentando sugerir, é que essa corporalidade talvez seja também informada pelas relações tecidas pela "alma". Assim, dentro desse "conflito" indígena entre pessoa e corporalidade, desse exercício ameríndio em fazer pessoas através de seus corpos, talvez, as festas de iniciação jarawara façam também pessoas por meio das relações tecidas com suas "almas". Se na Melanésia, descrita por Strathern (1988), o 'ritual masculino' visava mostrar o que corpo é capaz; possivelmente aqui, na festa mariná, um "ritual feminino", procura-se mostrar do que a 'alma' é capaz. Essas 'capacidades' possivelmente estão vinculadas ao 
'ser levada' (towakama), 'ser carregada' (weyena), 'ser trazida/conduzida' (kaki) - algo que as mulheres e os xamãs seriam/teriam em comum.

\section{Considerações Finais}

A ideia por trás dos argumentos que foram apresentados neste artigo é a de que temos uma preconcepção do que 'corpo' e 'pessoa' significam, fundada tanto em nossas formas de refletir como na maneira como nos concebemos. Essa forma de pensar é uma herança do pensamento dualista, que invade nossa concepção de ser humano e fornece o próprio vocabulário com o qual nos expressamos. Segundo essa concepção, sobrepomos discursos morais, advindos de nossa suposta 'humanidade', e biológicos, ligados a uma noção de 'espécie humana', em um complicado jogo de espelhos entre biologia e sociologia do qual não nos livramos até hoje (Ingold, 1995). Outros mundos nos mostram outras formas de pensar, na qual a distinção natureza e cultura está ausente, como na Melanésia (Strathern, 1980), ou se coloca invertida, como na Amazônia (Viveiros de Castro, 1996). Nesses mundos, os problemas e questões - e, sobretudo, as criatividades (Wagner) - são outros, muito diferentes dos nossos. As descrições etnográficas nos ajudam a perceber que não há nada de irrevogável em nossos corpos que os tornariam exclusivamente masculinos ou femininos, essa divisão é uma de nossas mais poderosas ficções (Strathern, 1988), também vinculada ao nosso conceito de procriação. Aqui a antropologia se posiciona para o feminismo 'multicultural', e de certa forma reforça a ideia de que a ideia de 'diferença' pode ir muito além do que nossos vocabulários permitem.

O movimento inverso, do feminismo 'como extensão' à antropologia, parece mostrar mais resistência por parte dos/as antropólogos/as. Mais de uma vez ouvi professores de antropologia dizendo que o debate feminista nada trouxe de consistente para a disciplina. Ouvi também professoras falando sobre "as feministas", como se houvesse um movimento mundial homogêneo, um bloco de 'feministas', ao qual elas não se interessariam. O que está implícito nessas afirmações é a ideia de que se as mulheres forem 'realmente boas/ capazes', elas não precisam do conhecimento feminista, em uma espécie 
de meritocracia na qual elas se saíram 'tão bem quanto' os homens (brancos, heterossexuais, de classe média). O que está ausente em tais discursos é que boa parte das pesquisadoras cujos trabalhos tiveram e têm grande repercussão na disciplina, e que vêm transformando a própria maneira de se pensar e fazer antropologia, se autodeclaram feministas - Marilyn Strathern, Donna Haraway, Isabelle Stengers, Lila Abu-Lughod, Henrietta Moore, Sherry Ortner, para mencionar apenas algumas. Dizer que o debate feminista nada trouxe à antropologia é "um escândalo não trivial", tomando de empréstimo a expressão de Haraway (2004). E mais do que isso, é uma forma de perpetuar um tipo de pensamento masculino que multiplica os escritos sobre os 'homens' e seus feitos, algo cuja eficácia vem se esgotando em um mundo que tem se revelado cada vez mais "pós-gênero".

\section{Notas}

1 Opta-se aqui e em outras passagens em traduzir o termo inglês 'of colour' por 'não branco' - ao invés de 'de cor', em português.

2 A este respeito ver Despret e Stengers (2011).

3 Utiliza-se aqui o termo Ocidental ao longo do artigo para me referir às sociedades que se encaixariam ao que Bruno Latour chamou de "modernos" [2001 (1991)]. Isto é, aquelas sociedades que acreditam ser diferentes das outras por 'dominarem a natureza' (por meio da ciência). Um dos traços mais marcantes na maneira 'moderna' ou Ocidental de pensar é a ideia de natureza e sociedade são categorias definidas a priori que não necessitariam explicações. Ao contrário, elas estão na base de todas as explicações: a natureza é aquilo que está dado, a sociedade o construído (Latour, 2001, p. 79).

4 Esses escritos são também conhecidos sob o nome de feminismo marxista e podem ser considerados uma variante da dicotomia público-doméstico e da divisão do trabalho colocada por Engels, onde a subordinação da mulher estaria vinculada à exclusão da esfera de produção (Moore, 1988; Rosaldo, 1974, p. 35). As autoras se baseiam na distinção de Engels, em The Origins of Family, entre a produção dos meios de existência e a redução de seres humanos ou, entre produção e reprodução (Haraway, 2004, p. 214; Moore; 1988).

5 O mais irônico é que a própria sociedade onde boa parte desse modelo foi construída, a sociedade britânica, foi uma sociedade onde quem cuidava das crianças eram babás: registra-se mais de dois milhões de babás (nannies) trabalhando para a classe média e alta britânica entre 1850 e 1939 (Boon apud Moore, 1988, p. 26), o momento em que muito desses pressupostos estavam sendo formulados. Um dado que sem dúvidas pode ser encontrado também em outras sociedades Ocidentais, como o Brasil por exemplo. O que aponta para a forma romantizada e idealizada de nossos construtos analíticos.

6 Emprega-se aqui o tempo presente do indicativo pois essas discussões continuam sendo atuais, assim como a multiplicidade dos posicionamentos feministas. 
7 “As lições que aprendemos enquanto mulheres deve ser a base para entendermos a nós mesmas como opressoras das mulheres do Terceiro Mundo com quem trabalhamos." (Ellen Pence apud Trinh, 1987, p. 11 tradução livre).

8 Patricia Hill Collins (2000, capítulo 3) faz uma descrição histórica detalhada do trabalho das mulheres afro-americanas da escravidão até os dias atuais, o qual não poderei me reter aqui, mas que demonstra os efeitos do racismo na esfera do trabalho.

9 Expressão do poeta afrodescendente e nordestino Arnaldo Xavier (Carneiro, 2000)

10 " [...] O viés eurocentrista do feminismo brasileiro, ao omitir a centralidade da questão de raça nas hierarquias de gênero presentes na sociedade, e ao universalizar os valores de uma cultura particular (a Ocidental) para o conjunto das mulheres, sem as mediações que os processos de dominação, violência e exploração que estão na base da interação entre brancos e não brancos, constitui-se em mais um eixo articulador do mito da democracia racial e do ideal de branqueamento" (González apud Carneiro, 2003, p. 120).

${ }^{11}$ O argumento lembra sem dúvidas, a pergunta: "As mulheres muçulmanas precisam ser salvas?", que intitula o último livro de Lila Abu-Lughod (2013), antropóloga especializada no estudo de populações beduínas e muçulmanas do Egito. AbuLughod argumenta que o vocabulário Ocidental de opressão, escolha e liberdade, não é adequado para descrever a vida dessas mulheres. A autora denuncia um tipo de mentalidade que quer justificar a interferência estrangeira, incluindo a invasão militar, em nome de socorrer as mulheres do Islamismo.

12 Fica claro que o conceito de "alma" tem uma conotação bem diferente da nossa "alma", sendo para a maior parte dos povos ameríndios algo como um 'sujeito-potencial' (Lima, 1996; Viveiros de Castro, 1996).

13 Elas são: sonhando (Kopenawa; Albert, 2010, p. 498), bebendo o mingau de banana na festa riahu (Kopenawa; Albert, 2010, p. 211 ); bebendo cachaça (Kopenawa; Albert, 2010, p. 353); quando se está doente/ com febre (Kopenawa; Albert, 2010, p. 177, 269, 381); quando se come comida desconhecida, como a comida dos brancos (Kopenawa; Albert, 2010, p. 421); quando uma pessoa fica com muita dor ou raiva (Kopenawa; Albert, 2010, p. 473), dentre tantas outras formas.

14 A palavra "festa" se aproxima mais daquilo que as pessoas vivem nesses eventos, que são grandes encontros entre pessoas, com um clima de muita comida, namoro, alegria e beleza.

\section{Referências}

ABU-LUGHOD, Lila. Writing women's worlds: bedouin stories. Los Angeles: University of California Press, 1993.

ABU-LUGHOD, Lila. Veiled Sentiments: Honor and Poetry in a Bedouin Society. Los Angeles: University of California Press, 2000.

ABU-LUGHOD, Lila. Do Muslim women need saving? Cambridge, Massachusetts: Harvard University Press, 2013.

AMOS, Valerie; PARMAR, Pratibha. Challenging Imperial Feminism. Feminist Review, [S.l.], n.17, p. 3-18, July, 1984. 
ANZALDÚA, Gloria. Borderland/La Frontera. San Francisco: Spinsters/ Aunt Lute, 1987.

ASAD, Talal. Introduction. In: ASAD, Talal (Ed). Anthropology and the colonial encounter. [S.l.]: Humanity Books, 1973.

BEHAR, Ruth; GORDON, Deborah. (Org.). Women Writing Culture. Los Angeles: University of California Press, 1995.

BUTLER, Judith. Gender Trouble: feminism and the subversion of identity. New York: Routledge, 1999.

CARNEIRO, Sueli. Matriarcado da miséria. Jornal Correio Braziliense, Brasília, Coluna Opinião, p. 5, 15 de setembro de 2000.

CARNEIRO, Sueli. "Mulheres em movimento". Estudos Avançados 17 (49), pp. 117-132, 2003.

COELHO DE SOUZA, Marcela. Parentes de sangue: incesto, substância e relação no pensamento Timbira. Mana, [S.l.], v. 10, n. 1, p. 25-60, 2004.

COLLIER, Jane; YANAGISAKO, Sylvia. Toward a Unified analysis of gender and kinship. In: COLLIER, Jane; YANAGISAKO, Sylvia (Ed.). Gender and Kinship. Essays toward a Unified Analysis. Stanford: Stanford University Press, 1987. p.14-50.

COLLINS, Patricia Hill. Black feminist thought: knowledge, consciousness and the politics of empowerment. Second Edition. New York: Routledge, 2000 (1990).

CLIFFORD, James. Introduction: Partial truths. In: MARCUS, George; CLIFFORD, James (Ed.). Writing Culture: the poetics and politics of ethnography. Los Angeles: University of California Press, 1986.

CLIFFORD, James. Sobre a autoridade etnográfica. In: CLIFFORD, James. A experiência etnográfica: antropologia e literatura no século XX. Rio de Janeiro: Editora da UFRJ, 2002. p. 17-62.

DE BEAUVOIR, Simone. Le deuxième sexe $\mathbf{I}$ : les faits et les mythes. Paris: Gallimard, 1949.

DESPRET Vinciane; STENGERS, Isabelle. Les faiseuses d'histoire: que font les femmes à la pensée? Paris: Les empêcheurs de penser en rond/La découverte, 2011.

ENGELS, Friedrich. The origins of the Family, Private Property, and the State. New York: Pathfinder Press, 1972 (1884).

FAUSTO-STERLING, Anne. The five sexes. The Sciences, [S.l.], p.20-25, March/April, 1993. 
HARAWAY, Donna. A Cyborg manifesto. Science, technology and socialistfeminist in the late twentieth century. Socialist Review, [S.l.], v. 80, p. 65-107, 1985.

HARAWAY, Donna. Saberes Localizados: a questão da ciência para o feminismo e o privilégio da perspectiva parcial. Cadernos Pagu, [S.l.], v. 5, p. 7-41, 1995 (1988).

HARAWAY, Donna. Gênero para um dicionário marxista: a política sexual de uma palavra. Cadernos Pagu, [S.l.], v. 22, p. 201-246, 2004 (1991).

INGOLD, Tim. Humanidade e Animalidade. Revista Brasileira de Ciências Sociais, [S.l.], n. 28, p. 39-53, 1995.

KOPENAWA, Davi ; ALBERT, Bruce. La chute du ciel: paroles d'un chaman yanomami. Paris: Terre Humaine/Plon, 2010.

LATOUR, Bruno. Jamais fomos modernos: ensaio de antropologia simétrica. Rio de Janeiro: Editora 34, 2001 (1991).

LIMA, Tania Stolze. O dois e seu múltiplo: reflexões sobre o perspectivismo em uma cosmologia tupi. Mana, [S.l.], v. 2, n. 2, p.21-47, 1996.

LORDE, Audre. The master's tools will never dismantle the master's house. In: MORAGA, Cherrie; ANZALDUA, Gloria (Ed.). This bridge called my back: Writing by radical women of color. Watertown, Massachusetts: Persephone Press, 2015 (1981). p. 94-97.

LORDE, Audre. Zami: a New Spelling of My Name. Trumansberg, New York: Crossing Press, 1982.

MAHMOOD, Saba. Feminist theory, embodiement and the docile agent: some reflections on the Egyptian Islamic revival. Cultural Anthropology, [S.l.], v. 16, n. 2, p. 202-236, 2001.

MAHMOOD, Saba. Politics of piety: the Islamic revival and the feminist subject. New Jersey: Princeton University Press, 2005.

MOHANTY, Chandra Talpade. Under Western Eyes: Feminist Scholarship and Colonial Discourse. Boundary 2, [S.l.], v. 12, n. 3, On Humanism and the University I: The discourse of Humanism, p. 333-358, Spring-Autumn 1984.

MAIZZA, Fabiana. Sobre as crianças-planta: o cuidar e o seduzir no parentesco jarawara. Mana, [S.l.], v.20, n.3, p.491-518, 2014.

MOORE, Henrietta. Feminism and Anthropology. Cambridge: Polity Press, 1988.

MOORE, Henrietta. A Passion for difference: essays on anthropology and gender. Bloomington: Indiana University Press, 1994. 
ORTNER, Sherry. Is Female to Male as Nature is to Culture?. In: ROSALDO, Michelle; LAMPHERE, Louise. (Ed.). Women, Culture and Society. Stanford: Stanford University Press, 1974. p. 67-87.

OVERING, Joana. Social time and social space in Lowland South American societies. Actes du XLII Congrès International des Américanistes. Paris, 1977.

PRECIADO, Paul Beatriz. Manifesto contrassexual: práticas subversivas de identidade. São Paulo: N-1 Edições, 2015.

RAPP, Rayna. Anthropology (Review essay). Signs 4, Chicago, n. 3, p.497513, 1979.

ROSALDO, Michelle. Women, culture and society: a theoretical overview. In: ROSALDO, Michelle; LAMPHERE, Louise. (Ed.). Women, Culture and Society. Stanford: Stanford University Press, 1974. p. 17-43.

SCHNEIDER, David. American Kinship: a cultural account. Chicago: The University of Chicago Press, 1980 (1968).

STOCKING JR., George. Race, culture and evolution: essays in the history of anthropology. Chicago: The University of Chicago Press, 1982 (1968).

STRATHERN, Marilyn. No nature, no culture: the Hagen case. In: STRATHERN, Marilyn; MACCORMACK, Carol. (Ed.). Nature, Culture and Gender. New York: Cambridge University Press, 1980. p. 174-222.

STRATHERN, Marilyn. The Gender of the Gift. Los Angeles: University of California Press, 1988.

STRATHERN, Marilyn. Parts and Wholes: refiguring relationships in a post-plural world. In: KUPER, Adam. (Org). Conceptualizing society. London: Routledge, 1992. p. 75-104.

STRATHERN, Marilyn. Necessidades de pais, necessidades de mães. Estudos feministas, v. 3, n. 2, p. 303-329, 1995.

STRATHERN, Marilyn. The concept of society is theoretically obsolete. In: INGOLD, Tim (Org). Key debates in Anthropology. London: Routledge, 1996. p. 45-80.

STRATHERN, Marilyn. Feminist critique. In: STRATHERN, Marilyn. Partial Connections. Walnut Creek: Altamira Press, 2004 (1991). p. 29-40.

STRATHERN, Marilyn. Uma relação incômoda: o caso do feminismo e da antropologia. Mediações, Londrina, v. 14, n. 2, p. 83-104, jul./dez. 2009 (1987). 
TRINH, T. Minh-ha. Difference: 'a Special Third World Women Issue'. Feminist Review, [S.l.], n. 25, p. 5-22, Spring, 1987.

VIVEIROS DE CASTRO, Eduardo. Os pronomes cosmológicos e o perspectivismo ameríndio. Mana, [S.l.], v. 2, n. 2, p. 115-144, 1996.

WAGNER, Roy. The invention of culture. Chicago/Londres: The University of Chicago Press. 1981.

WAGNER, Roy. The fractal person. In: GODELIER, Maurice; STRATHERN, Marilyn. (Org.). Big men and great men: personifications of power in Melanesia. Cambridge: Cambridge University Press, 1991. p. 159-173.

Recebido em 18/03/2017

Aceito em 07/05/2017 